\title{
Digital monitoring of broiler breeder behavior for assessment of thermal welfare
}

Danilo Florentino Pereira1, Irenilza de Alencar Nääs2, Daniella Jorge de Moura2

1 Professor, Universidade Estadual Paulista “Júlio de Mesquita Filho”, Faculdade de Administração de Empresas e Agronegócios, Campus Experimental de Tupã. Corresponding: Av. Domingos da Costa Lopes, 780, Jd. Unesp, Tupã-SP, Brazil, 17602-496. E-mail: danilo@tupa.unesp.br

2 Professor, Department of Agricultural Engineering, State University of Campinas. Corresponding: FEAGRI-UNICAMP, P.O.Box 6011, Campinas SP, Brazil, 13083-970.

\begin{abstract}
The assessment of welfare issues has been a challenge for poultry producers, and lately welfare standards needs to be reached in order to agree with international market demand. This research proposes the use of continuous behavior monitoring in order to contribute for assessing welfare. A software was developed using the language Clarium. The software managed the recording of data as well as the data searching in the database Firebird. Both software and the observational methodology were tested in a trial conducted inside an environmental chamber, using three genetics of broiler breeders. Behavioral pattern was recorded and correlated to ambient thermal and aerial variation. Monitoring video cameras were placed on the roof facing the used for registering the bird's behavior. From video camera images were recorded during the total period when the ambient was bright, and for analyzing the video images a sample of $15 \mathrm{~min}$ observation in the morning and $15 \mathrm{~min}$ in the afternoon was used, adding up to 30 min daily observation. A specific model so-called behavior was developed inside the software for counting specific behavior and its frequency of occurrence, as well as its duration. Electronic identification was recorded for 24h period. Behavioral video recording images was related to the data recorded using electronic identification. Statistical analysis of data allowed to identify behavioral differences related to the change in thermal environment, and ultimately indicating thermal stress and departure from welfare conditions.
\end{abstract}

Keywords. information system, broiler breeder, welfare, support decision systems.

\section{Introduction}

In animal production system the identification of behavioral parameters may help to manage production adequately and follow all processes involved. The use of RFID in female broiler breeders has been proved efficient for use in traceability processes by Curto (2002), and according to the author this can be an useful tool for input in getting data for building up a decision support system in animal production. Data recording and systematic analysis for decision making and control in animal production has been studied (Kebeler \& Schiefer, 1996; Zambalde et al.,1996) and software has been developed to attend market's demand mainly in herd and flock management.

There are several factors interfering in housed bird's welfare, among them there are environmental conditions, feeding systems and management control. Real time data recording inside broiler housing is difficult due to sensors accuracy. Savory \& Kostal (1997) describe the need for monitoring blood pressure as well as body core temperature and cardiac frequency of the birds in order to forecast wellbeing, and that this data could be acquired by using electronic sensors implanted in the birds. The authors used a RF transmission in $455 \mathrm{kHz}$ and the reading was done at $0.5 \mathrm{~m}$ distance. Kettlewell et al. (1997) monitored bird inside a transportation truck and used implanted transponders for recording cardiac and respiratory frequency using telemetry. In both cases environmental data were recorded using sensors placed in the birds ambient. The use of specific strategic and tool for measuring animal behavior has been describe by Donát (1991), where the author indicates the use of video cameras associated to specific software in a non-invasive way to register real time animal behavior. The author enhances the advantage of this method when compared to traditional observation technology. Duncan \& Mench (1993) in a research for recognizing suffering in housed animals proposed the use of behavioral analysis, particularly to identify specific state of frustration, pain or health status. It is not well known the way distinct birds respond to specific stress and suffering; however it is well described in the literature the housed broiler response to thermal stress (Tinôco, 2001). The animal behavior is commonly affected by the thermal environment as well as their social behavior. Their normal and/or aggressive interaction extend may indicate some degree of welfare. According to Graves (1982) the behavior is a way the animals interact with the ambient based on biological, morphological and physiological parameters. Puma et al. (2001) describe an individual electronic monitoring system for broiler feed and water consumption which was able to record continuously, and the results showed that there is a high degree of interaction with broiler feeding and water consumption 
according to environmental conditions. This data may be of help for real time management decision, as well as optimization of monitoring processes. Other authors used specific decision making systems for monitoring ammonia emission based on ingestion of specific diet (Frost et al., 2003), and the effect of a certain diet on broiler growth (Stacey et al., 2004). This research presents a software prototype for managing behavioral information, production and housing environment allowing the estimation of housed broiler breeders' welfare.

\section{Methodology}

The experiment was carried out inside a controlled environment chamber during nine days (July/August 2005). Thirty broiler breeders from three distinct genetics were used: 10 Cobb-500, 10 Ross, and 10 HybroPG. Each group of 10 was housed inside a box using a proportion of 5 female/male, and a bird density of 5 birds $/ \mathrm{m}^{2}$. All birds were exposed to the same environmental conditions: $\mathrm{T} 1=26.3^{\circ} \mathrm{C}, \mathrm{T} 2=29.5^{\circ} \mathrm{C}$ and $\mathrm{T} 3=$ $33^{\circ} \mathrm{C}$, simulating a heat wave and maintaining a constant ambient relative humidity of $75 \%$ (Tinôco, 2001). Behavioral response was recorded using a video camera installed on each box. Egg production, and hatching percentage were recorded manually. The response variables were analyzed as: 1 . The birds had an implant of a transponder in the foot, and each bird was weighted in the beginning of the experiment and at the end; 2. Readers were placed inside the boxes, specifically at the nest and the drinker and the movement of each individual was recorded as well as the time spent in each place. At the drinker besides the time spent in the local it was also evaluated the number of visits to the local, as when ambient temperature increases the evaporative cooling may occur near the drinker and the bird may prefer to stay there. The video images captured allowed to identity when the bird was actually drinking water or resting near the drinker; 3 . The number of eggs laid in each box represented the production of each genetic under the proposed treatment; 4 . Incubation and hatching was done after harvesting the eggs, cleaning them and placing them inside an incubator. After hatching the chicklings were weighted; 5. Behavior was observed following the ethogram showed in Table 1. The software was developed using the language Clarium, for managing the experiment, and to monitor the bird's behavior simultaneously along with environmental data.

Table 1. Ethogram of recorded behaviors

\begin{tabular}{|c|c|}
\hline Behavioral category & Definition \\
\hline Drinker & The bird is besides the drinker (independent of water ingestion) \\
\hline Drinking water & The bird is actually drinking water \\
\hline Chasing & The bird is running after another \\
\hline Dust Bathing & $\begin{array}{l}\text { A complex behavioral repertoire identified by the bird lying on its side displaying at } \\
\text { least one leg to the side and removing the litter towards the feathers }\end{array}$ \\
\hline Feather bristle & A noticeable increase in the feathers volume all over the body \\
\hline Foraging & The bird is pecking or scratching at the substrate. \\
\hline Laying down & The bird lay down in an attitude of resting (idle) \\
\hline Mounting & One bird tried to climb over the other \\
\hline Nesting & The bird is situated within the nest box. \\
\hline Open wings & $\begin{array}{l}\text { The bird open both wings at the same time for several times, including clapping them } \\
\text { together }\end{array}$ \\
\hline Pecking & $\begin{array}{l}\text { Sharp forward movements with the head towards an object or conspecific, as } \\
\text { sequences of pecking and scratching in the floor, and also included pecking at small } \\
\text { particles at the floor }\end{array}$ \\
\hline Pecking other & Sharp forward movements with the head towards other bird \\
\hline Preening & The beak is moving whilst touching another part of the body of the hen. \\
\hline Prostration & The bird was laying down with the head slightly bending down \\
\hline Resting Stationary & Either standing or sitting \\
\hline Running & $\begin{array}{l}\text { The bird performed a very rapid displacement for more than } 30 \mathrm{~cm} \text { long, in a random } \\
\text { direction without any specific reason }\end{array}$ \\
\hline Stretching & The act of the bird to spread one leg at the same time it spreads the wing \\
\hline Threatening & $\begin{array}{l}\text { An encounter in which a bird stands with the neck erect and feathers raised in front of } \\
\text { a second bird that had its head at a lower level }\end{array}$ \\
\hline \multicolumn{2}{|c|}{$\begin{array}{l}\text { Figure } 1 \text { shows the software flow diagram. Two computers were used for storing data, one PC and a } \\
\text { ver. Production data was inserted manually as the software input. An interface with environmental data } \\
\text { ording and database of video, and the user image was built, and a multiserial hardware was used for } \\
\text { necting six RFID readers and environmental data loggers recording. The server used two hardwares for } \\
\text { turing image (each one with four channels) and data came from six video cameras. After data collection }\end{array}$} \\
\hline
\end{tabular}


the researcher consulted the database using SQL and extract data which was statistically analyzed using the software Minitab ${ }^{\circledR}$.

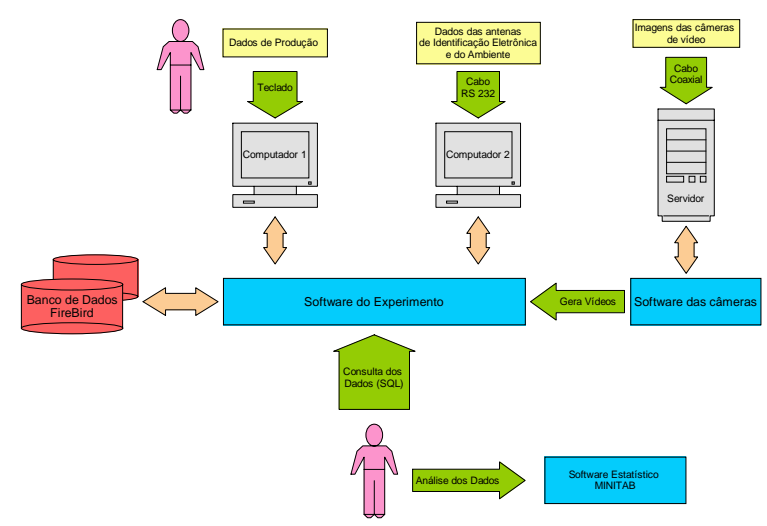

Figure 1. Diagram of the experimental procedure.

\section{Results and Discussion}

All data were registered and managed by the software that had the function of recording all experimental data in a relational Database named FireBird ${ }^{\circledR}$. This software was made into three modules: the first one was related to the configuration and systematic support data; the second refers to the recording itself, where the software compares inserting data at recording time with the previously registered data at the first module; and the third generates a summary of the data collected in real time for the researcher control. The screen where there is the control and data configuration is shown in Figure 2. The code transponder refers to the RFID number.

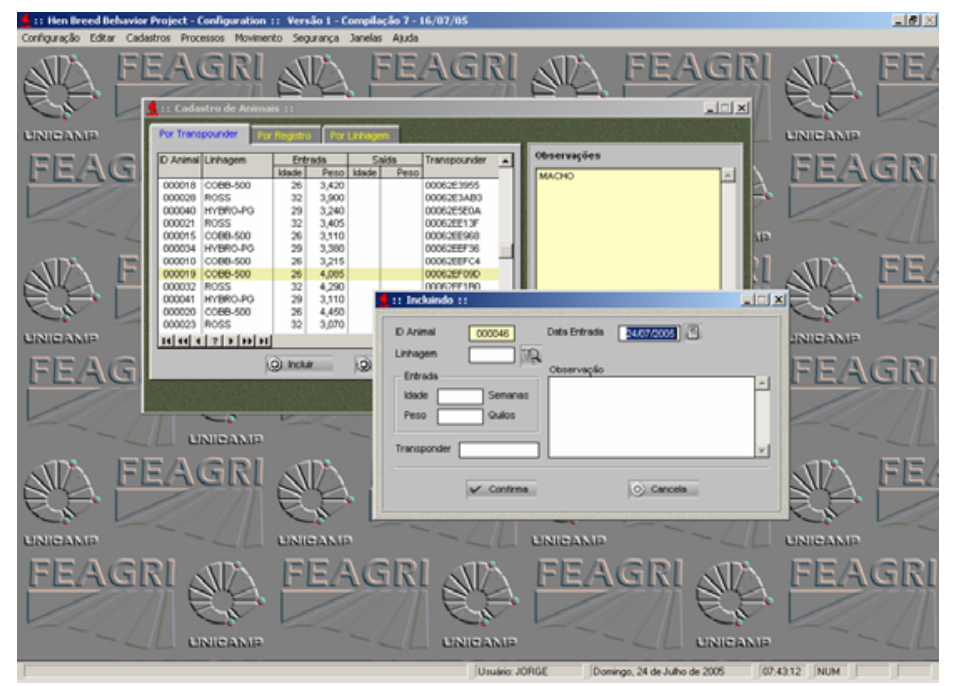

Figure 2. Data input screen. 
Figure 3. shows all software configuration options where data such as environmental psychometrics, RFID, etc, can be input

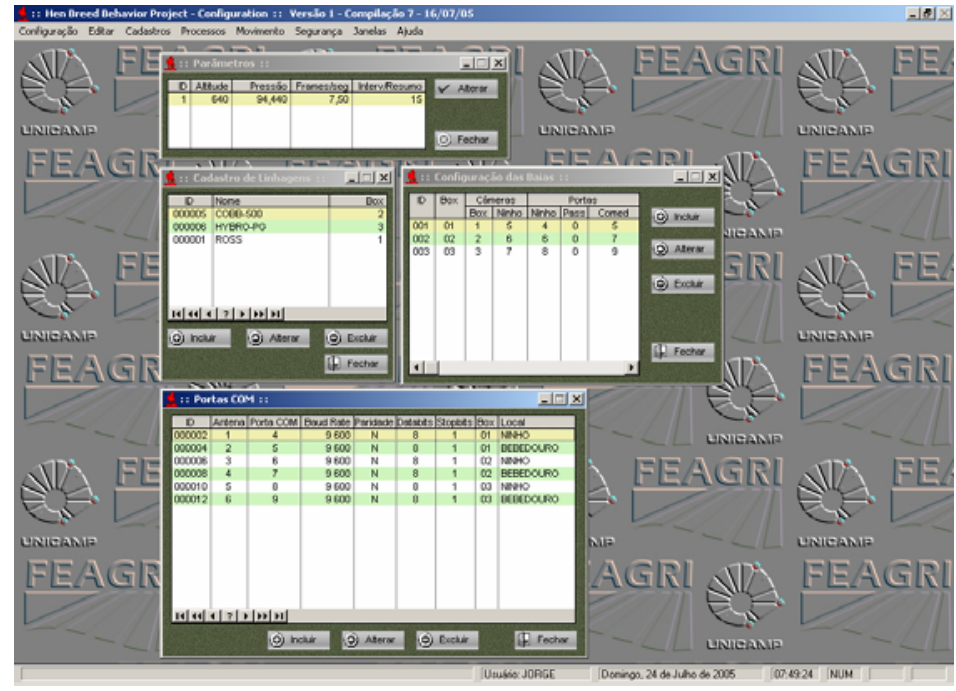

Figure 3. Configuration parameters screen.

The software also allows registration of fodder formulation. Data on diet and feeding was also used in the software. Production data (egg weight, volume, eggshell resistance, eggshell thickness, etc) input manually is shown in part of the screen of Figure 4. Other screens were used for hatching data.

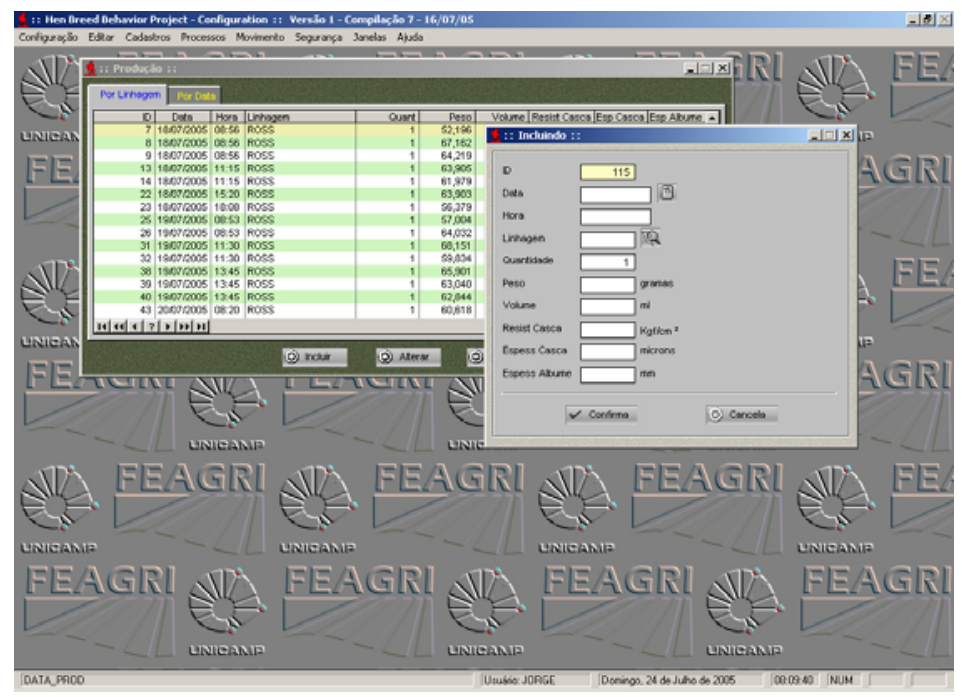

Figure 4. Production data input screen

Behavioral analysis was done by observing vídeo câmera recording as shown in Figure 5. Data was observed 15 min during the morning and $15 \mathrm{~min}$ in the afternoon. 


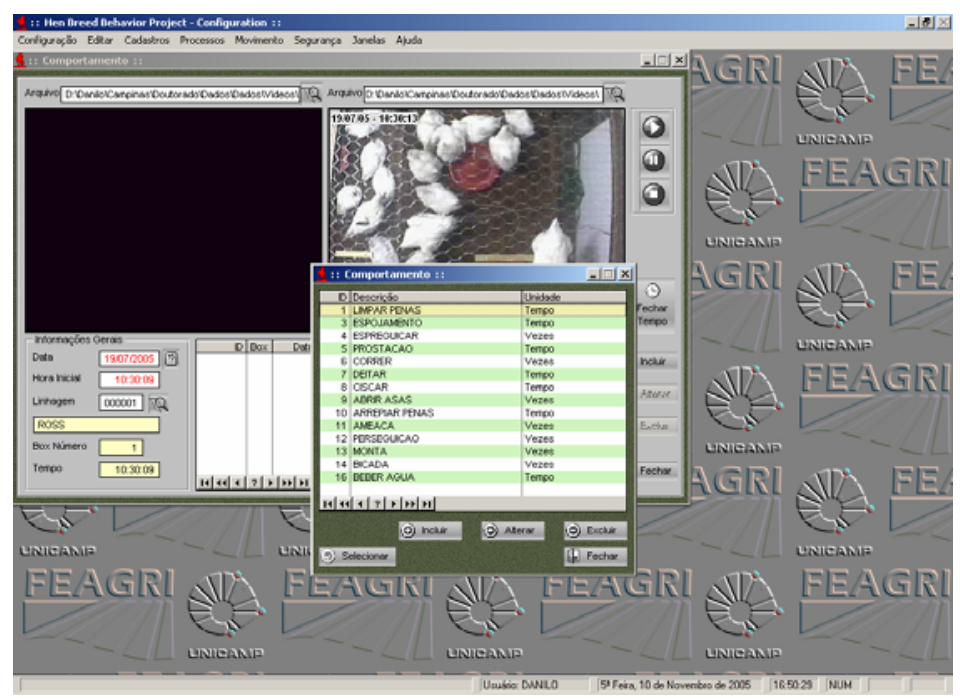

Figure 5. Behavior recording of birds screen

Another screens also had recording for physiological data such as body temperature and aerial environmental data (gases) Figure 6.

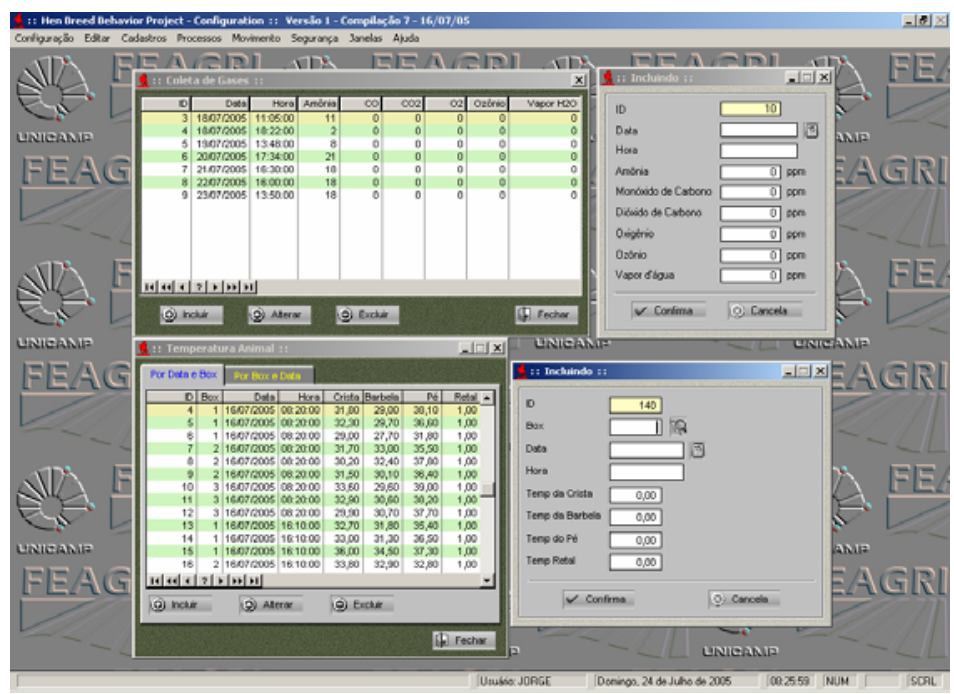

Figure 6. Data recording of surface body temperature.

This adopted recording systematic agreed with previous scientific research described in literature (Zambalde et al.,1996; Kebeler \& Schiefer ,1996; Frost et al.,1997). RFID was efficient in registering the use of physical space, as found by Curto (2002). Behavioral responses such as mounting, beaking and chasing, described in references (Bizeray et al., 2002; Estevez et al., 2003; Jong et al., 2003) were not noticed, probably due to observation time (30min).

The software made possible the total recording of data and to process its interactions as well. It was found that as mentioned by Graves (1982) the behavior reflected the interaction between the environment 
and the well being of the birds as they showed distinct behavior when exposed to distinct environmental scenarios, agreeing also with (Campos, 2000).

\section{Conclusion}

The software allowed the recording and processing of a large amount of data making possible the observational study in real time, and also estimating broiler breeder's thermal welfare. Further studies are needed for better use of this tool in welfare assessment studies.

\section{Acknowledgements}

The authors wish to thank FAPESP and PRODETAB-Embrapa for supporting this research, NUTRON ALIMENTOS for providing the fodder, and the producers Granja São José and Granja Ipê for donating the birds.

\section{References}

Bizeray, D., I. Estevez, C. Leterrier and J.M. Faure. 2002. Effects of increasing environmental complexity on the physical activity of broiler chickens. Applied Animal Behaviour Sci. 79 (1):27-41.

Curto, F.P.F. 2002. Study of the female broiler breeder's behavior in distinct environmental conditions using electronic ID and radio frequency. Unpublished PhD diss. Campinas, Brazil: State University of Campinas (in Portuguese).

Campos, E.J. O comportamento das aves. Revista Brasileira de Ciência Avícola, v. 2, n. 2, 2000. pp. 93113.

Costa, M.J.R.P. Princípios de etologia aplicados ao bem-estar das aves. Conferência Apinco de Ciência e Tecnologia Avícola, 2003. Anais... Campinas, 2003. pp. 169-177.

Curto, F. P. F. Estudo do comportamento de matrizes pesadas (frango de corte), em diferentes ambientes utilizando identificação eletrônica e rádio-freqüência - Programa de Pós-Graduação, Tese de Doutorado, Faculdade de Engenharia Agrícola, 2002.

Donát, P. Measuring Behavior: The Tools and the Strategies, Neuroscience \& Biobehavioral Reviews, v. 15, pp. 447-454, 1991.

Duncan, I.J.H., Mench, J.A. Behaviour as an indicator of welfare in various systems. Basic Biology and Welfare. Alternative Housing Systems, v. 7, 1993. pp. 69-76.

Estevez, I.; Keeling, L.J., Newberry, R.C. Decreasing aggression with increasing group size in young domestic fowl. Applied Animal Behaviour Science, v. 84, 2003. pp. 213-218.

Frost, A.R., Parsons, D.J., Stacey, K.F., Robertson, A.P., Welch, S.K., Filmer, D., Fothergill, A. Progress towards the development of an integrated management system for broiler chicken production. Computers and Eletronics in Agriculture, v. 39, 2003. pp.227-240.

Frost, A.R., Schofield, C.P., Beaulah, S.A., Mottram, T.T., Lines, J.A., Wathes, C.M. A review of livestock monitoring and the need for integrated systems. Computer and Eletronics in Agriculture, v. 17, 1997. pp.139-159.

Jong, I. C., Vooerst, S. V., Blokhuis, H. J. Parameters for qualification of hunger in broiler breeders. Physiology \& Behavior, v. 78, 2003. pp. 773-783.

Kebeler, T., Schiefer, G. Computer Aided Environmental Control to Support Environmental-ManagementSystems in Agricultural and Food-Industrial Production-Chains, Department of Agricultural Economics, 1996.

Kettlewell, P.J., Mitchell, M.A., Meeks, I.R. An implanteble radio-telemetry system for remote monitoring of heart rate and deep body temperature in poultry, Computers and Electronics in Agriculture, v. 17, pp. 161-175, 1997.

Puma, M.C., Xin, H., Gates, R.S., Burnhm, D.J. An instrumentation system for studying feeding and drinking behavior of individual poultry, Applied Engineering in Agriculture, ASAE, v. 17(3), pp.365374, 2001.

Savory, C. J., Kostal, L. Application of a radiotelemetry system for chronic measurement of bllod pressure, heart rate, EEG and activity in the chicken. Physiology \&Behavior, v. 61, n. 6, USA, 1997. pp. 963-969

Stacey, K.F., Parsons, D.J., Frost, A.R., Fischer, C., Filmer, D., Fothergill, A. An automatic growth and nutrition control system for broiler production. Biosystems Enginnering, v. 89, n. 3, 2004. pp. 363-371.

Zambalde, A. L., Jesus, J.C.S., Segre, L.M. Considerações Estratégicas sobre o Processo de Informatização das Empresas e Propriedades Rurais, Revista Agrosoft, n. 0, pp. 1-7, 1996. 